\title{
Estimation of Standard Splenic Volume in Saudi Arabian Adult Population: Using 3D Reconstruction of Abdominal CT Scan Images
}

\author{
Mohammad Aslam Siddiqui ${ }^{*}$, Ali Hassan A. Ali ${ }^{1,2}$, Mohamed Abdelmohsen Bedewi ${ }^{1}$, \\ Omar 0. Serhan ${ }^{3}$ \\ ${ }^{1}$ Anatomy \& Radiology Departments, Salman bin Abdulaziz University, Al-Kharj, KSA \\ ${ }^{2}$ Faculty of Medicine, Al Azhar University, Cairo, Egypt \\ ${ }^{3}$ King Khalid Hospital, Al-Kharj, KSA \\ Email: " draslam72@gmail.com, m.siddiqui@sau.edu.sa
}

Received 23 December 2013; revised 23 January 2014; accepted 1 February 2014

Copyright (C) 2014 by authors and Scientific Research Publishing Inc.

This work is licensed under the Creative Commons Attribution International License (CC BY).

http://creativecommons.org/licenses/by/4.0/

(c) (i) Open Access

\begin{abstract}
Purpose: Spleen is enlarged in a variety of clinical conditions including infectious, infiltrative, immunologic and malignant states. Evaluation of splenic size is important in every physical examination of the abdomen by a physician. Determination of its size by palpation can be extremely inaccurate because spleen is never palpable till it is enlarged 2 to 3 times its own size. The accurate diagnosis of splenic enlargement is a matter of considerable importance as it is a useful guide for arriving at a diagnosis of the disease. It is therefore of utmost importance to resort to a mechanism that will give us an accurate estimation of the size of spleen. Aim of this work was to determine the normal range of spleen dimensions in average adult Saudi Arabian population and compare it with the published data. Methods: CT scans of 34 adult patients (male and female) aged between 20 - 70 years, having no splenic disorders, were collected from department of radio-diagnosis King Khalid Hospital Al-Kharj, KSA. Splenic volume was measured by two methods-by volumetric software and the prolate ellipsoid formula. Results: The average splenic volume of all subjects was $161.42 \pm 54.91 \mathrm{~cm}^{3}$ with a range of $106-319 \mathrm{~cm}^{3}$. The average splenic volume of males was 196.95 $\pm 48.70 \mathrm{~cm}^{3}$ and that of female was $196.95 \pm 26.97 \mathrm{~cm}^{3}$. Conclusions: These results provide normative data for evaluating patients with splenic enlargement.
\end{abstract}

\section{Keywords}

Spleen; 3D Reconstruction; Computerized Tomography

\footnotetext{
*Corresponding author.
}

How to cite this paper: Siddiqui, M.A., Ali, A.H.A., Bedewi, M.A. andSerhan, O.O. (2014) Estimation of Standard Splenic Volume in Saudi Arabian Adult Population: Using 3D Reconstruction of Abdominal CT Scan Images. Open Journal of Internal Medicine, 4, 7-12. http://dx.doi.org/10.4236/ojim.2014.41002 


\section{Introduction}

Evaluation of splenic size is important in every physical examination of the abdomen by a physician. It is enlarged in a variety of clinical conditions including infectious, hematological, infiltrative, immunologic and malignant states.

Among infections, viral illnesses such as infectious mononucleosis are by far the most common cause in the young population. Others include malaria, kala azar (lieshmeniasis), brucellosis, salmonellosis, tuberculosis and bacterial endocarditis [1]. Hematological disorders include lymphomas and lymphatic leukemias, hemolytic anemia, chronic anemia, congenital spherocytosis and myeloproliferative diseases such as polycythemia verra and myelofibrosis.

Among immunological states are rheumatoid arthritis and systemic lupus erythematosus. Other important causes include cirrhosis of liver, portal hypertension, congestive heart failure, glycogen storage disorders, lymphoid tissue and hematological malignancies, Sarcoidosis and Amyloidosis.

Hypersplenism is a pancytopenia (low platelet count, white cell count and hemoglobin concentration) caused by splenic enlargement. Hematological disorders causing splenomegaly commonly, but not invariably, also cause enlargement of the liver. Hemolytic anemia causes mild splenomegaly without hepatomegaly.

The spleen has to increase in size three fold before it becomes palpable, so a palpable spleen always indicates splenomegaly.

\section{Spleen Anatomy}

The spleen is the largest lymphoid organ located in left hypochondriac region of abdomen wedged between stomach and diaphragm. It has two ends, two borders and two surfaces. It measures $1 \times 3 \times 5$ inches $(2.5 \times 7.5 \times$ $12.5 \mathrm{~cm}$ ), weighs $7 \mathrm{oz}$. and lies deep to left $9^{\text {th }}-11^{\text {th }}$ ribs. Its long axis lies along the line of $10^{\text {th }}$ rib [2]. Its superior (or posterior) end lies in line with spine of $10^{\text {th }}$ thoracic vertebra about $4 \mathrm{~cm}$ from mid line. The anterior (or inferior) end does not project beyond mid axillary line. It is completely enclosed in peritoneum which is derived from the left leaf of greater omentum [2].

Its anterior border is notched. The diaphragmatic surface is convex and applied to diaphragm. Visceral surface is related to stomach, left kidney, left suprarenal gland, left colic flexure and tail of pancreas. The hilum lies in the angle between stomach and left kidney [3].

The spleen is anchored to stomach by means of gastro-splenic ligament and to posterior abdominal wall by leino-renal ligament. Its lower end is supported by a fold of peritoneum that extends from left colic flexure to diaphragm, the phrenico-colic ligament. It is not attached to spleen itself. It is due to this ligament that the spleen doesn't extend vertically downward when enlarging. It rather moves downwards and medially towards umbilicus. In that case, the anterior border approaches to the costal margin and is identified by the presence of notch in it. A spleen must double its size before its anterior border passes beyond left costal margin.

The accurate diagnosis of splenic enlargement is a matter of considerable importance as it is a useful guide for arriving at a diagnosis of the disease. Determination of its size by physical examination is subjective and known to be inaccurate. Therefore, evaluation with radiologic imaging is required and is common.

Several studies utilizing a variety of imaging techniques such as computed tomography, scintigraphy, magnetic resonance imaging and sonography have been reported to determine splenic volume and hence to develop standards for splenic size [4]-[28].

Unfortunately, volume determination by 2D ultrasonogaphy can be inaccurate because of the variable, irregular contour of spleen and overlapping of its outline by bone, bowel gas or left kidney [10]. Volumetric measurements are most accurately obtained on computed tomography or magnetic resonance imaging [4] [14] [18] [21] [23].

New 3D reconstruction of CT images is more accurate than 2D ultrasonography [23] [27] computed tomography or magnetic resonance imaging. Because it gives us a three-dimensional image of the organ and can calculate its volume as well as the surface area. This is a new, novel and fast technique.

Since there are no data about the estimation of organ volumes using 3D technique in this part of the world, we decided to document the normal range of various dimensions of splenic volume and surface area in adult population of kingdom of Saudi Arabia.

Aim of this work was to determine the normal range of spleen size in average adult Saudi Arabian population, to compare it from splenic size of people in other regions of the world. 


\section{Materials and Methods}

50 CT scans of consecutive adult patients (male and female) aged between 20 - 70 years, having no splenic disorders, were collected from Department of Radio diagnosis, King Khalid Hospital as well as Salman Bin Abdul Aziz University Hospital, Al Kharj after seeking permission.

The patient's body weight and height were recorded at the time of the CT examination. Axial and cross-sectional images of spleen were collected from a computer attached to helical CT scan machine (Siemens SOMATOM Emotion 16 CT Scanner). The technical parameters were $130 \mathrm{kv}$ potential, $95 \mathrm{~mA}$ current, and 5 mm slice width with identical reconstruction index and rotation time of 0.6 secs.

Patients whose spleen appeared abnormal on CT scans were excluded. Following subjects were also excluded from study:

1) Subjects with pathologies potentially involving the spleen.

2) Subjects with hemoglobinopathies.

3) Subjects with skin infections at the area of the spleen.

4) Subjects in whom the entire length of the spleen could not be properly documented and those with previous splenectomy.

5) Subjects with lymphoproliferative disorders such as lymphomas, leukemias, etc.

6) Subjects with focal lesions and non-uniform parenchyma.

7) Subjects who had fever either at the time of the scan or within at least four weeks prior to the scan.

8) Gravid women.

Splenic volume was measured by two methods_-volume and surface rendering technique of Able 3D doctor software and prolate ellipsoid formula using analysis of CT Images. Able 3D doctor software uses stacks of cross-sectional images of any organ in a CT/MRI film to create 3D image of that organ.

CT scan data was placed in the software and the software created 3D picture of spleen (Figure 1). Then, with the help of software, volume and surface area were recorded (called as observed volume).

The volume of spleen was calculated manually by using the standard clinical prolate ellipsoid equation for spleen [0.524 $\times$ splenic index (max. length $\times$ max. width $\times$ max. thickness) $]$ [27].

Maximum length was taken as the greatest dimension of spleen on the longitudinal images. Maximum width was measured as the greatest overall dimension on transverse images and the maximum thickness as the distance between the hilum and the outer convex surface of the spleen keeping them perpendicular to each other [27].

Each dimension was rescanned and recorded three different times to the nearest millimeter and the median value obtained for accuracy of result.

Student's t-test was used for comparison of mean between the two sexes and considered significant with a $\mathrm{P}$ value of $<0.05$.

\section{Results}

Age of the subjects included in this study ranged between 20 to 70 years (Table 1). The average age of the participants was $49.59 \pm 16.70$ year. The mean age of male subjects was $50.61 \pm 19.41$ and that of female subjects $48.44 \pm 13.56$.

The mean splenic dimensions were in $\mathrm{cm}^{3}$ for volume (Table 2). The average splenic volume of the participants was $161.42 \pm 54.91 \mathrm{~cm}^{3}$. The mean splenic volume in males was $196.95 \pm 48.70$ and that in females $121.45 \pm 26.97$. Volume calculated by prolate ellipsoid formula was $285.80 \pm 64.31 \mathrm{~cm}^{3}$ in males and $220.21 \pm$ $64.86 \mathrm{~cm}^{3}$ in females. The average calculated splenic volume of the participants was $254.94 \pm 71.74 \mathrm{~cm}^{3}$.

\section{Discussion}

Splenomegaly is considered to be an important clinical finding because it results from a variety of disorders involving liver, hematopoietic and immune systems and infectious and malignant states. Early detection of this clinical sign is very important. Detection by physical examination is very late (spleen is never palpable till it is enlarged 2 to 3 times its own size) so a variety of imaging modalities have been used for this purpose. Among them ultrasonography [5] [6] [11]-[13] [15] [16] [19] [20] [25]-[28] has been the most widely used technique in recent past. Nowadays, CT scan and MRI are known to be a reliable and accurate method for assessing the volume of the spleen [4] [14] [18] [21] [23]. 


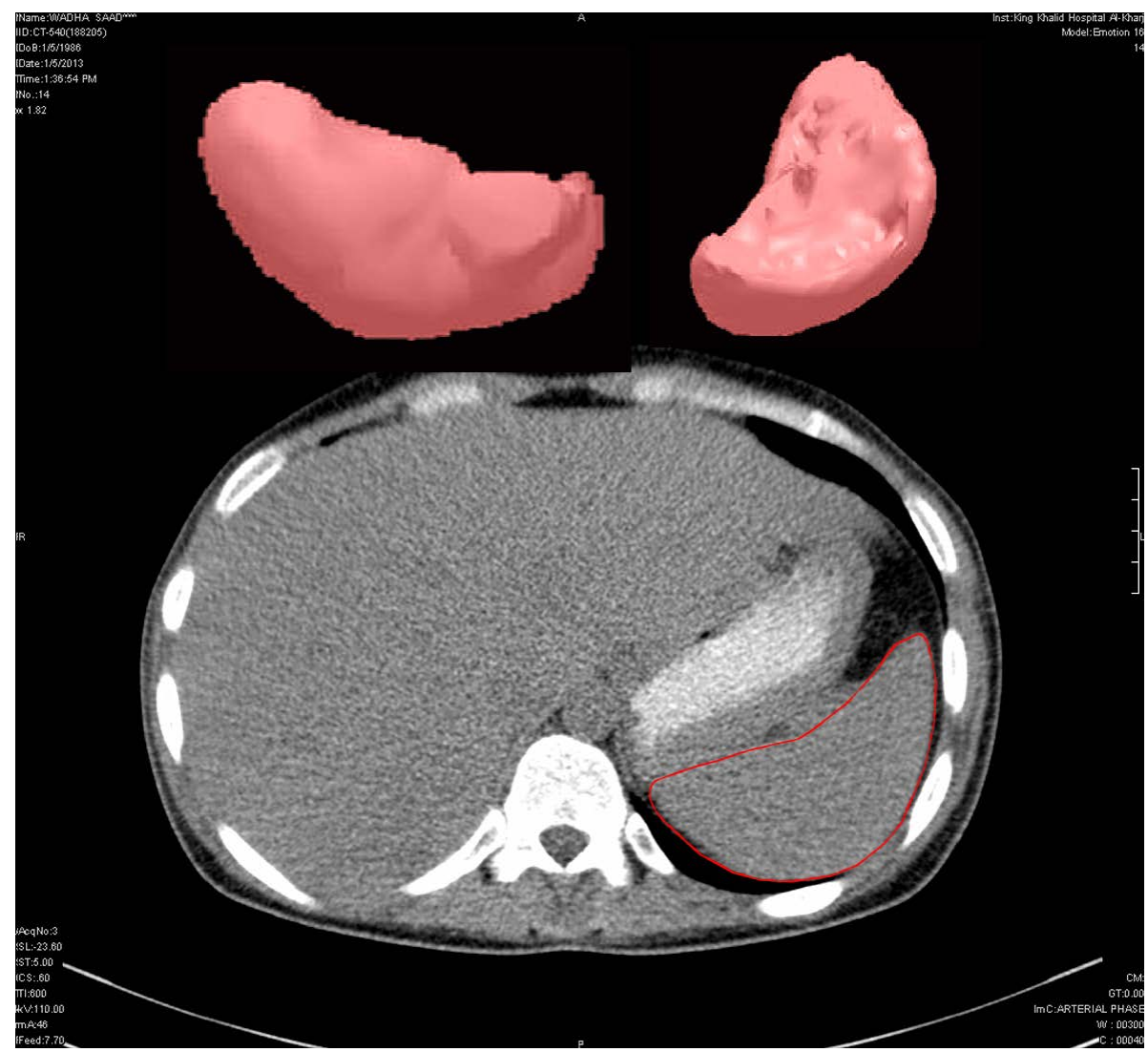

Figure 1. A CT scan of the abdomen and the 3D reconstructed image of the spleen.

Table 1. Physical standard of patients.

\begin{tabular}{ccccccc}
\hline \multirow{2}{*}{ Sex } & \multicolumn{5}{c}{ Physical standard of patients } \\
\cline { 2 - 7 } & Age (yrs.) & Weight (kg.) & Height $(\mathbf{c m})$ & Body surface area $\left.\mathbf{( m}^{2}\right)$ & Body mass index & Numbers of patients \\
\hline Male & $50.61 \pm 19.41$ & $90.28 \pm 23.31$ & $171.83 \pm 6.6$ & $2.95 \pm 0.23$ & $30.38 \pm 6.57$ & 18 \\
& \begin{tabular}{c}
$48.44 \pm 13.56$ \\
Female \\
\cline { 2 - 7 }
\end{tabular} & $\begin{array}{c}75.56 \pm 17.33 \\
\mathrm{P}<0.05\end{array}$ & $\begin{array}{c}163.56 \pm 6.0 \\
\mathrm{P}<0.05\end{array}$ & $2.68 \pm 0.20$ & $28.15 \pm 5.60$ & 16 \\
\hline
\end{tabular}

Table 2. Mean value and standard deviation of dimensions of spleen.

\begin{tabular}{cccc}
\hline Methods of measurement & Male (Mean \pm SD) & Female (Mean \pm SD) & Total (Mean \pm SD) \\
\hline 1) Volume rendering technique $\left(\mathrm{cm}^{3}\right)$ & $196.95 \pm 46.81$ & $121.45 \pm 26.97$ & $161.42 \pm 54.91$ \\
2) Prolate ellipsoid formula $\left(\mathrm{cm}^{3}\right)$ & $285.80 \pm 64.31$ & $220.21 \pm 64.86$ & $254.94 \pm 71.74$ \\
\hline
\end{tabular}

Significance level: $P<0.05$ between two sexes

Various studies were analyzed and their data compared with our study. Mustapha et al. (2010) [28] examined 374 adult African people by ultrasonography and found out the mean splenic volume to be $120 \mathrm{~cm}^{3}$. Rodrigues et al. (1995) [5] evaluated sonographic assessment of the size of the spleen in cadaveric spleens. They found out it to be $283.8 \mathrm{~cm}^{3} \pm 168.27$. The actual splenic volume calculated from water volume displacement was 147.5 $\mathrm{cm}^{3} \pm 81.46$. Hoefs et al. (1999) [15] calculated splenic volume in healthy volunteers to be $201 \pm 77 \mathrm{~cm}^{3}$ through liver-spleen scan by CT and MRI. They did not find any significant difference in the two sexes (male $\mathrm{cm}^{3}$ and female $\mathrm{cm}^{3}$ ). Spielmann et al. (2005) [6] reported splenic size in adult athletes to be $333.6 \pm 116.1 \mathrm{~cm}^{3}$ by ultrasonography. Loftus et al. (1999) [25] calculated splenic volume by water displacement and reported normal size to be $110 \pm 70 \mathrm{~cm}^{3}$. 
We found two studies calculating splenic volume by volumetric software just like we used it in our study. Harris et al. (2010) [4] measured splenic volume using volumetric software in 230 patients who underwent CT scan for various reasons. They reported splenic volume in Japanese people to be $127 \pm 62.9 \mathrm{~cm}^{3}$ in all subjects. We found the volume to be $161.42 \pm 54.91 \mathrm{~cm}^{3}$ in all Saudi subjects by using the same technique. Adil Asghar et al. (2011) [29] measured splenic volume using volumetric software in north Indian adult population and found it out to be $192 \pm 54.91 \mathrm{~cm}^{3}$ in males, $118.39 \pm 47.7 \mathrm{~cm}^{3}$ in females and over all $161.57 \pm 90.2 \mathrm{~cm}^{3}$. We found the splenic size in males to be $196.95 \pm 46.81 \mathrm{~cm}^{3}$ and in females to be $121.45 \pm 26.97 \mathrm{~cm}^{3}$. They found a significant difference in two sexes. We have also found a significant difference in two sexes.

\section{Conclusion}

We have provided the normative data of normal splenic volume in Saudi Arabian adults which can be used in certain clinical situation in which objective measurement of splenic dimensions and comparisons with standard of normal splenic volume would be useful.

\section{Acknowledgements}

This project was supported by the Deanship of Scientific Research at Salman bin Abdulaziz University, Al Kharj, KSA. We are thankful to the deanship for this support.

\section{References}

[1] Douglas, G., Nicol, F. and Robertson, C. (2009) Macleod’s Clinical Examination. 12th Edition, Churchill Livingstone, Elsevier, Philadelphia.

[2] Sinnatamby, C.S. (2006) Last's Anatomy: Regional and Applied. 11th Edition, Churchill Livingstone, Elsevier, Saunders, New York.

[3] Moore, K.L. (1992) Clinically Oriented Anatomy. 3rd Edition, Williams and Wilkins, Philadelphia.

[4] Harris, A., Kamishima, T., Hao, H.Y., Kato, F., et al. (2010) Splenic Volume Measurements on Computed Tomography Utilizing Automatically Contouring Software and Its Relationship with Age, Gender, and Anthropometric Parameters. European Journal of Radiology, 75, 97-101. http://dx.doi.org/10.1016/j.ejrad.2009.08.013

[5] Rodrigues Junior, A.J., Rodrigues, C.J., Germano, M.A., Rasera Junior, I. and Cerri, G.G. (1995) Sonographic Assessment of Normal Spleen Volume. Clinical Anatomy, 8, 252-255. http://dx.doi.org/10.1002/ca.980080403

[6] Spielmann, A.L. DeLong, D.M. and Kliewer, M.A. (2005) Sonographic Evaluation of Spleen Size in Tall Healthy Athletes. American Journal of Roentgenology, 184, 45-49. http://dx.doi.org/10.2214/ajr.184.1.01840045

[7] Zhang, B. and Lewis, S.M. (1987) Use of Radionuclide Scanning to Estimate Size of Spleen in Vivo. Journal of Clinical Pathology, 40, 508-511. http://dx.doi.org/10.1136/jcp.40.5.508

[8] Niederau, C., Sonnenberg, A. and Muller, J.E. (1983) Sonographic Measurements of the Normal Liver, Spleen, Pancreas, and Portal Vein. Radiology, 149, 537-540.

[9] Friis, H., Ndhlovu, P., Mduluza, T., Kaondera, K., Franke, D., Vennervald, B.J., et al. (1996) Ultrasonographic Organometry: Liver and Spleen Dimensions among Children in Zimbabwe. Tropical Medicine \& International Health, 1, 183-190. http://dx.doi.org/10.1111/j.1365-3156.1996.tb00024.x

[10] Hidaka, H., Nakazawa, T., Wang, G., et al. (2010) Reliability and Validity of Splenic Volume Measurement by 3-D Ultrasound. Hepatology Research, 40, 979-988. http://dx.doi.org/10.1111/j.1872-034X.2010.00705.X

[11] Ishibashi, H., Higuchi, N., Shimamura, R., Hirata, Y., Kudo, J. and Niho, Y. (1991) Sonographic Assessment and Grading of Spleen Size. Journal of Clinical Ultrasound, 19, 21-25. http://dx.doi.org/10.1002/jcu.1870190106

[12] Rosenberg, H.K., Markowitz, R.I., Kolberg, H., Park, C., Hubbard, A. and Bellah, R.D. (1991) Normal Splenic Size in Infants and Children: Sonographic Measurements. American Journal of Roentgenology, 157, 119-121. http://dx.doi.org/10.2214/ajr.157.1.2048509

[13] Pietri, H. and Boscaini, M. (1984) Determination of a Splenic Volumetric Index by Ultrasonic Scanning. Journal of Ultrasound in Medicine, 3, 19-23.

[14] Henderson, J.M., Heymsfield, S.B., Horowitz, J. and Kutner, M.H. (1981) Measurement of Liver and Spleen Volume by Computed Tomography. Radiology, 141, 525-527.

[15] Hoefs, J.C., Wang, F.W., Lilien, D.L., Walker, B. and Kanel, G. (1999) A Novel, Simple Method of Functional Spleen Volume Calculation by Liver-Spleen Scan. Journal of Nuclear Medicine, 40, 1745-1755.

[16] Frank, K., Linhart, P., Kortsik, C. and Wohlenberg, H. (1986) Sonographic Determination of Spleen Size: Normal Di- 
mensions in Adults with a Healthy Spleen. Ultraschall in der Medizin, 7, 134-137. http://dx.doi.org/10.1055/s-2007-1011931

[17] Dittrich, M., Milde, S., Dinkel, E., Baumann, W. and Weitzel, D. (1983) Sonographic Biometry of Liver and Spleen Size in Childhood. Pediatric Radiology, 13, 206-211. http://dx.doi.org/10.1007/BF00973157

[18] Mazonakis, M., Damilakis, J., Maris, T., Prassopoulos, P. and Gourtsoyiannis, N. (2000) Estimation of Spleen Volume Using MR Imaging and a Random Marking Technique. European Radiology, 10, 1899-1903. http://dx.doi.org/10.1007/s003300000551

[19] Al-Imam, O., Suleiman, A. and Khuleifat, S. (2000) Ultrasound Assessment of Normal Splenic Length and Spleen-ToKidney Ratio in Children. Eastern Mediterranean Health Journal, 6, 514-516.

[20] Konus, O.L., Ozdemir, A., Akkaya, A., Erbas, G., Celik, H. and Isik, S. (1998) Normal Liver, Spleen, and Kidney Dimensions in Neonates, Infants, and Children: Evaluation with Sonography. American Journal of Roentgenology, 171, 1693-1698. http://dx.doi.org/10.2214/ajr.171.6.9843315

[21] Prassopoulos, P., Daskalogiannaki, M., Raissaki, M., Hatjidakis, A. and Gourtsoyiannis, N. (1997) Determination of Normal Splenic Volume on Computed Tomography in Relation to Age, Gender and Body Habitus. European Radiology, 7, 246-248. http://dx.doi.org/10.1007/s003300050145

[22] Mittal, R. and Chowdhary, D.S. (2010) A Pilot Study of the Normal Measurements of the Liver and Spleen by Ultrasonography in the Rajasthani Population. Journal of Clinical and Diagnostic Research, 4, 2733-2736.

[23] Breiman, R.S., Beck, J.W. and Korobkin, M. (1982) Volume Determinations Using Computed Tomography. American Journal of Roentgenology, 138, 329-333. http://dx.doi.org/10.2214/ajr.138.2.329

[24] Haddad-Zebouni, S., Hindy, R., Slaba, S., Aoun, N., Mourani, C., Abi Ghanem, S., et al. (1999) Ultrasonographic Evaluation of the Kidney, Liver and Spleen Size in Children. Archives of Pediatrics, 6, 1266-1270. http://dx.doi.org/10.1016/S0929-693X(00)88887-9

[25] Loftus, W.K., Chow, L.T.C. and Metreweli, C. (1999) Sonographic Measurement of Splenic Length: Correlation with Measurement at Autopsy. Journal of Clinical Ultrasound, 27, 71-74. http://dx.doi.org/10.1002/(SICI)1097-0096(199902)27:2<71::AID-JCU4>3.0.CO;2-U

[26] Loftus, W.K. and Metreweli, C. (1997) Normal Splenic Size in a Chinese Population. Journal of Ultrasound in Medicine, 16, 345-347.

[27] Yetter, E.M., Acosta, K.B., Olson, M.C. and Blundell, K. (2003) Estimating Splenic Volume: Sonographic Measurements Correlated with Helical CT Determination. American Journal of Roentgenology, 181, 1615-1620. http://dx.doi.org/10.2214/ajr.181.6.1811615

[28] Mustapha, Z., Tahir, A., Tukur, M., Bukar, M. and Lee, W.K. (2010) Sonographic Determination of the Normal Spleen Size in an Adult African Population. European Journal of Radiology, 75, 133-135. http://dx.doi.org/10.1016/j.ejrad.2009.09.025

[29] Asghar, A., Agrawal, D., Yunus, S.M., Sharma, P.K., Zaidi, S.H.H. and Sinha, A. (2011) Standard Splenic Volume Estimation in North Indian Adult Population: Using 3D Reconstruction of Abdominal CT Scan Images. Anatomy Research International, 2011, 5 p. 